JAMA

Online article and related content current as of May 18, 2010.

\section{Risk Factors and Outcomes Associated With First-Trimester Fetal Growth Restriction}

Dennis O. Mook-Kanamori; Eric A. P. Steegers; Paul H. Eilers; et al.

JAMA. 2010;303(6):527-534 (doi:10.1001/jama.2010.78)

http://jama.ama-assn.org/cgi/content/full/303/6/527

eSupplement

http://jama.ama-assn.org/cgi/content/full/303/6/527/DC1

Contact me if this article is corrected.

This article has been cited 3 times.

Contact me when this article is cited.

Pediatrics; Child Development; Women's Health; Pregnancy and Breast Feeding; Prognosis/ Outcomes

Contact me when new articles are published in these topic areas.

Related Articles published in the same issue
First-Trimester Determination of Complications of Late Pregnancy Gordon C. S. Smith. JAMA. 2010;303(6):561.
Subscribe

http://jama.com/subscribe

Permissions

permissions@ama-assn.org

http://pubs.ama-assn.org/misc/permissions.dtl
Email Alerts

http://jamaarchives.com/alerts

Reprints/E-prints

reprints@ama-assn.org 


\section{Risk Factors and Outcomes Associated With First-Trimester Fetal Growth Restriction}

\begin{tabular}{l} 
Dennis O. Mook-Kanamori, MD, MSc \\
\hline Eric A. P. Steegers, MD, PhD \\
\hline Paul H. Eilers, PhD \\
\hline Hein Raat, MD, PhD \\
\hline Albert Hofman, MD, PhD \\
\hline Vincent W. V. Jaddoe, MD, PhD \\
\hline
\end{tabular}

$\mathrm{F}$ ETAL DEVELOPMENTAL ADAPTAtions due to adverse environmental exposures may affect the structure, physiology, and function of various organ systems leading to fetal growth restriction and increased risks of metabolic and cardiovascular disease in adulthood. ${ }^{1,2} \mathrm{Hu}$ man growth and development rates are highest during the first trimester of pregnancy, when essential fetal organ development is completed. ${ }^{3}$ Adverse first-trimester fetal exposures might have permanent consequences for fetal and postnatal health.

First-trimester fetal crown to rump length is used in obstetric care practice for pregnancy dating, assuming no growth variation. ${ }^{4}$ Studies among women with a regular menstrual cycle suggest that maternal age, ethnicity, and fetal sex are associated with fetal crown to rump length. ${ }^{5,6}$ Maternal smoking, alcohol consumption, and folic acid supplement use influence birth weight, ${ }^{7,8}$ but their associations with first-trimester fetal growth are not known. Two studies suggested that first-trimester fetal growth restriction increases the risks of low birth weight and small size for gestational age..$^{9,10}$ The relationship between first-trimester fetal growth

For editorial comment see p 561.

Context Adverse environmental exposures lead to developmental adaptations in fetal life. The influences of maternal physical characteristics and lifestyle habits on firsttrimester fetal adaptations and the postnatal consequences are not known.

Objective To determine the risk factors and outcomes associated with firsttrimester growth restriction.

Design, Setting, and Participants Prospective evaluation of the associations of maternal physical characteristics and lifestyle habits with first-trimester fetal crown to rump length in 1631 mothers with a known and reliable first day of their last menstrual period and a regular menstrual cycle. Subsequently, we assessed the associations of first-trimester fetal growth restriction with the risks of adverse birth outcomes and postnatal growth acceleration until the age of 2 years. The study was based in Rotterdam, the Netherlands. Mothers were enrolled between 2001 and 2005.

Main Outcome Measures First-trimester fetal growth was measured as fetal crown to rump length by ultrasound between the gestational age of 10 weeks 0 days and 13 weeks 6 days. Main birth outcomes were preterm birth (gestational age $<37$ weeks), low birth weight $(<2500 \mathrm{~g})$, and small size for gestational age (lowest fifth birth centile). Postnatal growth was measured until the age of 2 years.

Results In the multivariate analysis, maternal age was positively associated with firsttrimester fetal crown to rump length (difference per maternal year of age, $0.79 \mathrm{~mm}$; $95 \%$ confidence interval [Cl], 0.41 to 1.18 per standard deviation score increase). Higher diastolic blood pressure and higher hematocrit levels were associated with a shorter crown to rump length (differences, $-0.40 \mathrm{~mm} ; 95 \% \mathrm{Cl},-0.74$ to -0.06 and -0.52 $\mathrm{mm} ; 95 \% \mathrm{Cl},-0.90$ to -0.14 per standard deviation increase, respectively). Compared with mothers who were nonsmokers and optimal users of folic acid supplements, those who both smoked and did not use folic acid supplements had shorter fetal crown to rump lengths (difference, $-3.84 \mathrm{~mm} ; 95 \% \mathrm{Cl},-5.71$ to -1.98 ). Compared with normal first-trimester fetal growth, first-trimester growth restriction was associated with increased risks of preterm birth $(4.0 \%$ vs $7.2 \%$; adjusted odds ratio [OR], 2.12; $95 \% \mathrm{Cl}, 1.24$ to 3.61$)$, low birth weight (3.5\% vs $7.5 \%$; adjusted OR, $2.42 ; 95 \% \mathrm{Cl}, 1.41$ to 4.16$)$, and small size for gestational age at birth (4.0\% vs $10.6 \%$; adjusted $\mathrm{OR}, 2.64 ; 95 \% \mathrm{Cl}, 1.64$ to 4.25$)$. Each standard deviation decrease in firsttrimester fetal crown to rump length was associated with a postnatal growth acceleration until the age of 2 years (standard deviation score increase, 0.139 per 2 years; $95 \% \mathrm{Cl}, 0.097$ to 0.181 ).

Conclusions Maternal physical characteristics and lifestyle habits were independently associated with early fetal growth. First-trimester fetal growth restriction was associated with an increased risk of adverse birth outcomes and growth acceleration in early childhood.

JAMA. 2010;303(6):527-534

www.jama.com

Author Affiliations: The Generation R Study Group (Drs Mook-Kanamori and Jaddoe); Departments of Epidemiology (Drs Mook-Kanamori, Hofman, and Jaddoe), Pediatrics (Drs Mook-Kanamori and Jaddoe), Obstetrics \& Gynecology (Dr Steegers), Biostatistics (Dr Eilers), and Public Health (Dr Raat),
Erasmus Medical Center, Rotterdam, the Netherlands.

Corresponding Author: Vincent W. V. Jaddoe, MD PhD, The Generation R Study Group (AE-006), Erasmus Medical Center, PO Box 2040, 3000 CA Rotterdam, the Netherlands (v.jaddoe@erasmusmc.nl). 


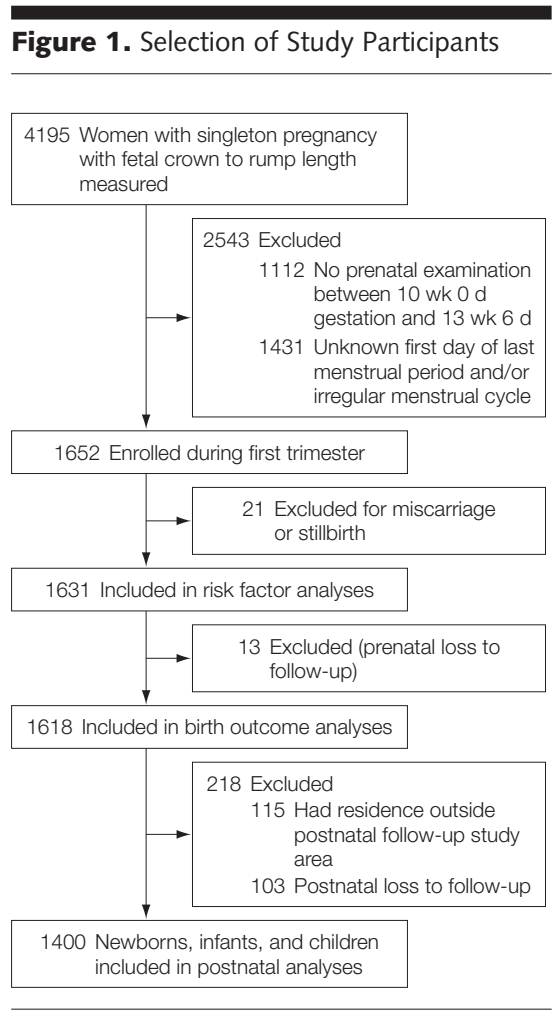

restriction and postnatal health outcomes remains unknown.

In a population-based prospective cohort study among mothers with a known first day of the last menstrual period, we examined the associations of several maternal physical characteristics and lifestyle habits with firsttrimester fetal growth. Subsequently, we examined whether first-trimester fetal growth restriction is associated with the risks of adverse birth outcomes and growth adaptations during fetal life and early childhood.

\section{METHODS}

\section{Study Design and Cohort}

This study was embedded in the Generation R Study, a population-based prospective cohort study from early fetal life onward in Rotterdam, the Netherlands. ${ }^{11}$ The study has been approved by the medical ethics committee of the Erasmus Medical Center, Rotterdam, the Netherlands. Written informed consent for both maternal and child data was obtained from all mothers.
Mothers enrolled between 2001 and 2005. Fetal crown to rump length was measured in 4195 mothers with singleton pregnancies (FIGURE 1). Of these mothers, 3083 had measurements within the recommended gestational age range of 10 weeks 0 days and 13 weeks 6 days. ${ }^{12}$ Mothers who did not undergo prenatal examinations within this time frame $(n=1112)$ and those in whom pregnancy ended with miscarriage or stillbirth $(n=21)$ were excluded, since gestational age at time of death with subsequent arrest of fetal growth could not be ascertained. ${ }^{13}$ Mothers with neither a known first day of the last menstrual period nor a regular menstrual cycle of 28 plus or minus 4 days were excluded $(n=1431)$, leaving 1631 participants for the analyses. First day of the last menstrual period was obtained from the referring letter from the community midwife or hospital. This date was confirmed with the mother at the ultrasound visit and additional information on the regularity and cycle duration was obtained.

The prevalence of preeclampsia and (gestational) diabetes was $1.7 \%$ and $1.1 \%$, respectively. Since exclusion of these women did not materially change our results, they were included in the analyses.

\section{Maternal Risk Factors}

Information on maternal age, educational level, smoking habits, alcohol use, folic acid supplement use, parity, and mode of conception were obtained through self-administered questionnaire at enrollment (response rate 93\%). Since fetal growth is known to vary between ethnicities, ${ }^{14}$ participating mothers were requested to give details regarding the country of birth of their parents. This information was used to classify participants' ethnic background according to Statistics Netherlands, as previously described in detail. ${ }^{14}$ Weight and height were measured without shoes or heavy clothing and body mass index was calculated (weight in kilograms divided by height in meters squared). Blood pressure was mea- sured with the validated Omron 907 automated digital oscillometric sphygmomanometer (OMRON Healthcare Europe B.V. Hoofddorp, the Netherlands). After being seated in an upright position for at least 5 minutes, the mean value of 2 blood pressure readings over a 60-second interval was documented. Hematocrit and hemoglobin levels were available from firsttrimester blood samples (success rate $84 \%$ ).

\section{Fetal Ultrasounds}

In our research facility, we measured first-trimester ( $<14$ weeks) crown to rump length in a true midsagittal plane with the genital tubercle and the fetal spine longitudinally in view. ${ }^{15}$ The maximum length from cranium to the caudal rump was measured as a straight line. Transvaginal scanning was performed in the case of limited visibility by transabdominal scanning. In the second trimester (median weeks, 20.3; 90\% range, 19.1-22.0), and third (median weeks, 30.1; 90\% range, 29.0-32.0), we measured fetal head circumference, biparietal diameter, abdominal circumference, and femur length to the nearest millimeter using standardized ultrasound procedures. ${ }^{16}$ Estimated fetal weight was calculated using the formula by Hadlock et al. ${ }^{17}$ Ultrasound examinations were performed using an Aloka model SSD-1700 (Tokyo, Japan) or the ATLPhilips Model HDI 5000 (Seattle, Washington).

Standard deviation scores for all fetal growth characteristics were constructed. ${ }^{16}$ Intraclass correlation coefficients for intraobserver and interobserver reproducibility of crown to rump length measurements were 0.998 and 0.995 , respectively. ${ }^{18}$

\section{Birth Outcomes}

Date of birth, birth anthropometrics (weight, length, head circumference) and offspring sex were obtained from community midwife and hospital registries. Gestational age and sexadjusted standard deviation scores for birth weight, length, and head circum- 
ference were constructed using growth standards from Usher and McLean. ${ }^{19}$ Small size for gestational age at birth was defined within our study population (lowest fifth birth centile), preterm birth as a gestational age at birth of less than 37 weeks, and low birth weight as a birth weight of less than $2500 \mathrm{~g}$.

\section{Postnatal Growth}

Well-trained staff in community health centers obtained postnatal growth characteristics (weight, length, and head circumference) using standardized procedures. ${ }^{11}$ Based on the routine health care program, periodic visits were scheduled for 8 age periods (1, 2, 3, 4, $6,11,14$, and 24 months). Actual median (90\% range) ages (by weeks) were: 4.7 (3.6-6.6); 9.7 (8.7-12.6); 14.4 (13.0$16.9) ; 19.0$ (17.4-21.2); 26.7 (23.7$31.0) ; 47.6(43.5-53.0) ; 61.8$ (59.368.2); and 107.1 (102.1-118.2). For postnatal growth characteristics, we obtained standard deviation scores using Dutch reference growth curves (Growth Analyzer 3.0, Dutch Growth Research Foundation, Rotterdam, the Netherlands).

\section{Statistical Analysis}

First, we performed a nonresponse analysis by comparing characteristics of mothers who were included in the analyses to those who were excluded due to an unknown or unreliable first day of last menstrual period or an irregular menstrual cycle using the $t$, Mann-Whitney $U$, and $\chi^{2}$ tests. Also, we compared birth characteristics of children included in the postnatal analyses to those who were not.

Second, we created gestational age-adjusted standard deviation scores for each individual fetal measurement in our study (eAppendix, available online at http://www.jama .com). We used fetal sex and gestational age-adjusted linear regression models to assess the associations of each determinant with first-trimester fetal crown to rump length separately. To enable comparison of the effect estimates between risk factors, we pre- sent our results as change per standard deviation score for continuous variables. Subsequently, all factors associated with crown to rump length were included in 1 multivariate linear regression model. We also examined interactions between lifestyle exposures (smoking, alcohol use, and folic acid supplement use). Since the timing of ovulation is dependent of the duration of the menstrual cycle, these models were adjusted for the duration of the last menstrual cycle.

Third, we examined the associations of first-trimester fetal growth restriction, defined as gestational ageadjusted crown to rump length in the lowest $20 \%$ of the population, with the risk of adverse birth outcomes (preterm birth, small size for gestational age, and low birth weight) using univariate logistic regression models. To account for potential confounding, these models were subsequently adjusted for factors associated with fetal crown to rump length.

Finally, we studied the associations of first-trimester fetal crown to rump length with growth characteristics in the second and third trimesters and from birth until the age of 24 months using sex-adjusted linear regression models. To assess the associations of firsttrimester fetal crown to rump length with longitudinally measured growth rates in childhood, we performed unbalanced repeated measures regression analysis (eAppendix).

With a sample size of 1631 women and assuming a power of 0.80 and a significance level of .05 (2-sided), we were able to detect an effect of 0.07 standard deviations. When multiple comparisons were performed, the significance level was adjusted using the Bonferroni correction. For all analyses, missing values were imputed with the mean for continuous variables or an additional category for categorical variables. We found similar results based on imputed and complete data sets. Statistical analyses were performed using the Statistical Analysis System version 9.1.3 (SAS Statistical Soft- ware, Cary, North Carolina) and the Statistical Package of Social Sciences version 15.0 (SPSS Inc, Chicago, Illinois).

\section{RESULTS}

\section{Maternal and Fetal Characteristics}

Maternal and fetal characteristics are shown in TABLE 1 . Nonresponse analysis showed that mothers with a known first day of the last menstrual period and a reliable menstrual cycle were older, more highly educated, more often white, and more frequently users of folic acid supplements (all $P<.001)$ (eTable 1, available at http://www.jama .com). Of all newborns, infants, and children, $7 \%$ were excluded from postnatal follow-up studies because of relocation outside of the study area and $6 \%$ were lost to follow-up for other reasons. Postnatal follow-up data were available in the remaining $87 \%$ of all newborns, infants, and children in the study. Those who were not included in the postnatal analyses had a lower birth weight (difference, 156 g; 95\% CI, 61 to $251 ; P<.001$ ) and a smaller size for gestational age at birth (difference, 0.50 weeks; $95 \% \mathrm{CI}, 0.18$ to $0.83 ; P=.009$ ) compared with those included in these analyses (eTable 2).

\section{Risk Factors of First-Trimester Fetal Growth Variation}

In the univariate analyses, higher maternal age, folic acid supplement use, and having had a previous childbirth were positively associated with fetal crown to rump length (TABLE 2 ). Higher diastolic blood pressure and hematocrit level, a secondary education only, Surinamese ethnicity, and smoking were associated with a shorter fetal crown to rump length. Maternal anthropometrics were not associated with fetal crown to rump length.

In the multivariate analyses, the associations of maternal age ( 0.10 standard deviation score; $95 \%$ CI, 0.05 to $0.16 ; P<.001)$ per standard deviation increase in age $(1=4.68$ years $)$, diastolic blood pressure ( -0.05 standard deviation score; $95 \%$ CI, -0.10 to -0.01 ; $P=.03)$ per standard deviation in- 
crease in blood pressure $(1=9.52 \mathrm{~mm}$ $\mathrm{Hg}$ ), hematocrit level ( -0.07 standard deviation score; $95 \%$ CI, -0.12 to -0.01 ; $P=.02)$ per standard deviation increase in hematocrit level $(1=2.50 \%)$, smoking $(-0.13$ standard deviation score; $95 \% \mathrm{CI},-0.25$ to $-0.01 ; P=.03)$, and folic acid supplement use (0.17 standard deviation score; $95 \% \mathrm{CI}, 0.33$ to $0.01 ; P=.03$ ) with fetal crown to rump length remained significant (TABLE 3 ). After multiple testing adjustment (6 independent risk factors), the associations with diastolic blood pressure, smoking, and folic acid supplement use were no longer significant. We also observed a dose-response association between the number of cigarettes smoked daily by the mother and fetal crown to rump length $(P=.04)$. A stratified analysis according to gestational age indicated no interaction between gestational age and risk factors except for maternal age, in which the effect size increased with increasing gestational age $(P=.002$; eTable 3$)$.

We observed an interaction of maternal smoking and folic acid

\begin{tabular}{|c|c|}
\hline Characteristic & Value \\
\hline $\begin{array}{l}\text { Maternal } \\
\text { Age at intake, median ( } 90 \% \text { range), y }\end{array}$ & $31.4(21.9-37.9)$ \\
\hline Gestational age at intake, mean (SD), wk & $12.4(0.8)$ \\
\hline Height, mean (SD), cm & $169(7.0)$ \\
\hline Weight, median (90\% range), kg & $67.0(53.0-92.5)$ \\
\hline Body mass index, median (90\% range) ${ }^{a}$ & $23.5(19.4-32.0)$ \\
\hline $\begin{array}{l}\text { Blood pressure at intake, mean (range), } \mathrm{mm} \mathrm{Hg} \\
\text { Systolic }\end{array}$ & $117(12.4)$ \\
\hline Diastolic & $69(9.5)$ \\
\hline Hematocrit level, mean (SD), \% & $36.7(2.5)$ \\
\hline Hemoglobin level, mean (SD), g/dL & $12.4(0.9)$ \\
\hline $\begin{array}{l}\text { Education, No. (\%) } \\
\quad \text { Primary }\end{array}$ & $93(6.0)$ \\
\hline Secondary & 617 (39.6) \\
\hline Higher & $847(54.4)$ \\
\hline $\begin{array}{l}\text { Race/ethnicity, No. (\%) } \\
\text { Dutch/white }\end{array}$ & $1127(71.6)$ \\
\hline Surinamese & $88(5.6)$ \\
\hline Turkish & $97(6.2)$ \\
\hline Moroccan & $56(3.6)$ \\
\hline Indonesian & $48(3.0)$ \\
\hline Other & $158(10.0)$ \\
\hline Smoking, No. (\%) & 355 (24.3) \\
\hline Alcohol use, No. (\%) & $888(60.5)$ \\
\hline Folic acid supplement use, No. (\%) & $1117(85.1)$ \\
\hline Parity, No. primiparous (\%) & $962(59.3)$ \\
\hline Conception, No. spontaneous (\%) & $1552(98.9)$ \\
\hline $\begin{array}{l}\text { Fetal } \\
\quad \text { First trimester crown to rump length, } \mathrm{mm}\end{array}$ & $60.9(11.4)$ \\
\hline Male sex, No. (\%) & $817(50.5)$ \\
\hline Birth head circumference, mean (SD), cm & $34.0(1.7)$ \\
\hline Birth length, mean (SD), cm & $50.4(2.4)$ \\
\hline Birth weight, mean (SD), g & $3454(565)$ \\
\hline Gestational age at birth, median (90\% range), wk & $40.1(37.1-42.0)$ \\
\hline Preterm birth (<37 wk), No. (\%) & $75(4.6)$ \\
\hline Small for gestational age (<fifth birth centile), No. (\%) & $86(5.3)$ \\
\hline Low birth weight (<2500 g), No. (\%) & $69(4.3)$ \\
\hline
\end{tabular}

intake $(P<.001)$, indicating that mothers who smoked and did not use folic acid supplements had a smaller fetal crown to rump length growth $(-0.52$ standard deviation score; $95 \% \mathrm{CI},-0.78$ to -0.25 ; or $-3.84 \mathrm{~mm}$; 95\% CI, -5.71 to -1.98 ) compared with nonsmoking mothers who used folic acid supplements (eFigure 2). We did not observe other interactions between smoking, alcohol use, and folic acid supplement use (all $P>.1$ ).

\section{First-Trimester Fetal Growth Restriction and Adverse Birth Outcomes}

Small first-trimester fetal crown to rump length, defined as the lowest $20 \%$, was associated with an increased risk of being born preterm (4.0\% vs $7.2 \%)$, small size for gestational age ( $4.0 \%$ vs $10.6 \%)$, or with a low birth weight ( $3.5 \%$ vs $7.5 \%$ ) (TABLE 4 ). Using the same data, sensitivity analyses with a cutoff of the lowest $10 \%$ instead of the lowest $20 \%$ for crown to rump length showed similar effect estimates for preterm birth $(4.2 \%$ vs $8.8 \%$; odds ratio [OR], 2.43; 95\% CI, 1.28 to $4.59 ; P=.006)$, small size for gestational age at birth $(4.5 \%$ vs $12.5 \%$; OR, 2.50; 95\% CI, 1.42 to $4.41 ; P=.001)$, and low birth weight (3.7\% vs $9.4 \%$; OR, 2.70; 95\% CI, 1.43 to $5.09 ; P=.002)$.

\section{First-Trimester Fetal Growth Restriction and Growth in Fetal Life and Early Childhood}

First-trimester fetal crown to rump length was positively associated with second- and third-trimester head circumference, femur length, and estimated fetal weight (FIGURE 2). The associations of first-trimester fetal crown to rump length with biparietal diameter and abdominal circumference are shown in eTable 4. Firsttrimester crown to rump length was associated with postnatal weight until the age of 11 months (0.061 standard deviation score; $95 \%$ CI, 0.005 to 0.117 ; $P=.03$ ) and with postnatal head circumference and femur length until 
the age of 14 months ( 0.080 standard deviation score; $95 \% \mathrm{CI}, 0.012$ to $0.148 ; P=.02$ and 0.065 standard deviation score; $95 \% \mathrm{CI}, 0.007$ to 0.122 ; $P=.03$, respectively). No associations between crown to rump length and growth parameters at the age of 2 years were found. In these children, each standard deviation decrease in first-trimester fetal crown to rump length was associated with an accelerated growth rate in weight and height during the first 2 years (increase of 0.139 standard deviation score per 2 years; 95\% CI, 0.097 to 0.181; $P<.001$ and 0.128 standard deviation score per 2 years; $95 \%$ CI, 0.085 to $0.173 ; P<.001$, respectively). These associations were independent of birth weight.

\section{COMMENT}

This study showed that maternal physical characteristics and lifestyle habits are associated with first-trimester crown to rump length as a measure of firsttrimester fetal growth. Shorter firsttrimester crown to rump length was associated with increased risks of preterm birth, small size for gestational age at birth, and low birth weight. Further-

Table 2. Maternal Risk Factors of First-Trimester Variation in Fetal Crown to Rump Length Adjusted for Fetal Sex and Gestational Age $(\mathrm{N}=1631)^{\mathrm{a}}$

\begin{tabular}{|c|c|c|c|c|}
\hline Risk Factor & $\begin{array}{l}\text { Effect Size for Fetal } \\
\text { Crown to Rump } \\
\text { Length }(95 \% \mathrm{Cl}), \mathrm{mm}\end{array}$ & $\begin{array}{c}P \\
\text { Value }\end{array}$ & $\begin{array}{l}\text { Effect Size for } \\
\text { Standard Deviation } \\
\text { Score }(95 \% \mathrm{Cl})\end{array}$ & $\begin{array}{c}P \\
\text { Value }\end{array}$ \\
\hline Age at intake (1 SD $=4.68 \mathrm{y})$ & $0.84(0.51$ to 1.18$)$ & $<.001$ & $0.11(0.06$ to 0.16$)$ & $<.001$ \\
\hline Height $(1 \mathrm{SD}=7.07 \mathrm{~cm})$ & $0.17(-0.17$ to 0.50$)$ & .33 & $0.02(-0.03$ to 0.06$)$ & .50 \\
\hline Weight (1 SD = $12.42 \mathrm{~kg})$ & $0.09(-0.25$ to 0.42$)$ & .62 & $0.01(-0.04$ to 0.05$)$ & .85 \\
\hline Body mass index $(1 \mathrm{SD}=4.08 \text { units })^{\mathrm{b}}$ & $-0.01(-0.35$ to 0.33$)$ & .96 & $-0.01(-0.06$ to 0.04$)$ & .81 \\
\hline Blood pressure at intake, mean SD, $\mathrm{mm} \mathrm{Hg}$ & $-0.31(-0.64$ to 0.02$)$ & .07 & $-0.05(-0.09$ to 0.002$)$ & .06 \\
\hline Diastolic (1 SD = 9.46) & $-0.44(-0.77$ to -0.10$)$ & .01 & $-0.06(-0.11$ to -0.01$)$ & .01 \\
\hline Hematocrit level (1 SD = 2.50\%) & $-0.57(-0.95$ to -0.20$)$ & .003 & $-0.07(-0.13$ to -0.02$)$ & .008 \\
\hline Hemoglobin level (1 SD = 0.94 g/dL) & $-0.56(-0.91$ to -0.20$)$ & .002 & $-0.06(-0.12$ to -0.01$)$ & .01 \\
\hline \multicolumn{4}{|l|}{ Education } & .33 \\
\hline Secondary & $-0.76(-1.47$ to -0.06$)$ & .03 & $-0.10(-0.26$ to 0.01$)$ & .07 \\
\hline Higher & 0 [Reference] & & 0 [Reference] & \\
\hline \multicolumn{4}{|l|}{ Race/ethnicity } & \\
\hline Surinamese & $-2.22(-3.69$ to -0.74$)$ & .003 & $-0.26(-0.47$ to -0.05$)$ & .02 \\
\hline Turkish & $-0.29(-1.69$ to 1.11$)$ & .68 & $-0.05(-0.25$ to 0.16$)$ & .65 \\
\hline Moroccan & $1.23(-0.58$ to 3.04$)$ & .18 & $0.21(-0.08$ to 0.49$)$ & .11 \\
\hline Indonesian & $1.30(-0.65$ to 3.25$)$ & .19 & $0.20(-0.08$ to 0.49$)$ & .15 \\
\hline Other & $0.44(-0.69$ to 1.57$)$ & .45 & $0.0(-0.08$ to 0.24$)$ & .35 \\
\hline \multicolumn{5}{|l|}{$\begin{array}{c}\text { Smoking } \\
\text { No }\end{array}$} \\
\hline Yes, all & $-1.20(-2.01$ to -0.34$)$ & .004 & $-0.16(-0.28$ to -0.05$)$ & .007 \\
\hline Yes, $<5 / d$ & $-0.91(-1.97$ to 0.16$)$ & .09 & $-0.13(-0.28$ to 0.02$)$ & .09 \\
\hline Yes, 5-9/d & $-0.83(-2.26$ to 0.62$)$ & .26 & $-0.12(-0.32$ to 0.09$)$ & .27 \\
\hline Yes, $\geq 10 / d$ & $-1.74(-3.38$ to -0.10$)$ & .04 & $-0.21(-0.44$ to 0.03$)$ & .08 \\
\hline Alcohol & $0.40(-0.31$ to 1.11$)$ & .27 & $0.05(-0.05$ to 0.15$)$ & .34 \\
\hline No & 0 [Reference] & & 0 [Reference] & \\
\hline \multicolumn{4}{|l|}{ Folic acid supplement use } & \\
\hline No & $-1.10(-2.14$ to -0.07$)$ & .04 & $-0.14(-0.29$ to 0.01$)$ & .06 \\
\hline \multicolumn{4}{|l|}{ Parity } & \\
\hline$\geq 1$ & 0.83 (0.16 to 1.51$)$ & .02 & $0.11(0.02$ to 0.21$)$ & .02 \\
\hline \multicolumn{3}{|l|}{ Spontaneous conception } & 0 [Reference] & \\
\hline No & -0.61 (-3.74 to 2.53$)$ & .70 & $-0.14(-0.59$ to 0.31$)$ & .55 \\
\hline $\begin{array}{l}\text { Abbreviation: } \mathrm{Cl} \text {, confidence interval. } \\
\text { aValues are calculated as regression coefficients }(9 \\
\text { rump length ( } \mathrm{mm} \text { or standard deviation score) per } \\
\text { difference in fetal crown to rump length comparec } \\
\text { b Calculated as weight in kilograms divided by heigh }\end{array}$ & $\begin{array}{l}\text { eir corresponding } P \text { values. } \\
\text { tandard deviation of the risk } \\
\text { rence group. } \\
\text { quared. }\end{array}$ & $\begin{array}{l}\text { Dus variable } \\
\text { categorica }\end{array}$ & $\begin{array}{l}\text { ct estimates represent the chr } \\
\text { mous variables, the effect es }\end{array}$ & $\begin{array}{l}\text { crown to } \\
\text { esent the }\end{array}$ \\
\hline
\end{tabular}


more, shorter first-trimester crown to rump length was associated with accelerated growth rates in early childhood.

We used the first day of the last menstrual period to determine gestational age at crown to rump length measurement. To avoid misclassification, we included only pregnant women with a known and reliable first day of the last menstrual period and a regular menstrual cycle of approximately 28 days. Misclassification of gestational age might still be an issue since the postconceptional age at the time of ultrasound is dependent on the timing of ovulation and implantation, which we were unable to measure. For example, the duration of the follicular phase, after which ovulation occurs, has been shown to also be associated with several maternal factors such as maternal age and smoking. ${ }^{20}$ Furthermore, dating of the last menstrual period can be confounded by recall bias. ${ }^{21}$ However, all our results remained after adjustment for the duration of last menstrual cycle, which is highly associated with the timing of ovulation. Moreover, even with a known and reliable last menstrual period, a certain fraction of women with regular cycles have early or delayed ovulation. Nonetheless, restriction to participants who had a gestational age based on last menstruation within 7 days of a gestational age based on crown to rump length (93\%) did not materially change our effect estimates.

Mothers with a known and reliable last menstrual period were on average older, taller, more likely to be higher educated and Dutch, consume alcohol, and use folic acid supplements than those with an unreliable menstrual cycle. Our effect estimates would be biased if the associations between risk factors and firsttrimester fetal growth would differ between individuals included and not included in the analysis. This seems unlikely. ${ }^{22}$

\begin{tabular}{|c|c|c|c|c|}
\hline Risk Factor & $\begin{array}{l}\text { Effect Size for Fetal } \\
\text { Crown to Rump Length } \\
(95 \% \mathrm{Cl}), \mathrm{mm}\end{array}$ & $\begin{array}{c}P \\
\text { Value }\end{array}$ & $\begin{array}{l}\text { Effect Size for } \\
\text { Standard Deviation } \\
\text { Score }(95 \% \mathrm{Cl})\end{array}$ & $\begin{array}{c}P \\
\text { Value }\end{array}$ \\
\hline Age at intake (1 SD $=4.68 \mathrm{y})$ & 0.79 (0.41 to 1.18$)$ & $<.001$ & 0.10 (0.05 to 0.16$)$ & $<.001$ \\
\hline Diastolic blood pressure $(1 \mathrm{SD}=9.52 \mathrm{~mm} \mathrm{Hg})$ & $-0.40(-0.74$ to -0.06$)$ & .02 & $-0.05(-0.10$ to -0.01$)$ & .03 \\
\hline Hematocrit level $(1 \mathrm{SD}=2.50 \%)^{b}$ & $-0.52(-0.90$ to -0.14$)$ & .006 & $-0.07(-0.12$ to -0.01$)$ & .02 \\
\hline Hemoglobin level (1 SD = $0.946 \mathrm{~g} / \mathrm{dL})^{\mathrm{b}}$ & $-0.52(-0.89$ to -0.16$)$ & .005 & $-0.06(-0.11$ to -0.01$)$ & .02 \\
\hline $\begin{array}{l}\text { Smoking }(\text { no }=\text { reference) } \\
\text { Yes, all }\end{array}$ & $-0.98(-1.79$ to -0.16$)$ & .02 & $-0.13(-0.25$ to -0.01$)$ & .03 \\
\hline Yes, $<5 / d$ & $-0.62(-1.67$ to 0.42$)$ & .24 & $-0.08(-0.23$ to 0.07$)$ & .29 \\
\hline Yes, 5-9/d & $-0.66(-2.09$ to 0.76$)$ & .36 & $-0.09(-0.30$ to 0.11$)$ & .38 \\
\hline Yes, $\geq 10 / d$ & $-1.25(-2.87$ to 0.36$)$ & .13 & $-0.14(-0.38$ to 0.09$)$ & .23 \\
\hline $\begin{array}{l}\text { Folic acid supplement use (yes = reference) } \\
\text { No }\end{array}$ & $-1.33(-2.41$ to -0.24$)$ & .02 & $-0.17(-0.33$ to -0.01$)$ & .03 \\
\hline $\begin{array}{l}\text { Parity }(0 \text { = reference }) \\
\quad \geq 1\end{array}$ & $0.27(-0.43$ to 0.97$)$ & .45 & $0.04(-0.06$ to 0.14$)$ & .57 \\
\hline
\end{tabular}

\begin{tabular}{|c|c|c|c|c|c|c|}
\hline & \multicolumn{2}{|c|}{ Crown to Rump Length } & \multirow{2}{*}{$\begin{array}{c}\text { Unadjusted OR } \\
(95 \% \mathrm{Cl})^{\mathrm{a}}\end{array}$} & \multirow{2}{*}{$\begin{array}{c}P \\
\text { Value }\end{array}$} & \multirow{2}{*}{$\begin{array}{l}\text { Adjusted OR } \\
(95 \% \mathrm{Cl})^{\mathrm{a}}\end{array}$} & \multirow{2}{*}{$\begin{array}{c}P \\
\text { Value }\end{array}$} \\
\hline & $<20$ th Percentile, No. (\%) & $\geq 20$ th Percentile, No. (\%) & & & & \\
\hline $\begin{array}{c}\text { Preterm birth } \\
<37 \text { wk }\end{array}$ & $23(7.2)$ & $52(4.0)$ & $1.85(1.11-3.07)$ & .02 & $2.12(1.24-3.61)$ & .006 \\
\hline$\geq 37 \mathrm{wk}$ & $298(92.8)$ & $1245(96.0)$ & & & & \\
\hline $\begin{array}{l}\text { Small size for gestational age } \\
\quad<\text { Fifth birth centile }\end{array}$ & $34(10.6)$ & $52(4.0)$ & $2.84(1.81-4.45)$ & .001 & $2.64(1.64-4.25)$ & .001 \\
\hline$\geq$ Fifth birth centile & $287(89.4)$ & $1245(96.0)$ & & & & \\
\hline $\begin{array}{l}\text { Low birth weight } \\
<2500 \mathrm{~g}\end{array}$ & $24(7.5)$ & $45(3.5)$ & $2.24(1.35-3.75)$ & .002 & $2.42(1.41-4.16)$ & .001 \\
\hline$\geq 2500 \mathrm{~g}$ & $297(92.5)$ & $1252(96.5)$ & & & & \\
\hline
\end{tabular}


Children lost to follow-up were on average smaller at birth, which is a risk factor for postnatal growth acceleration. ${ }^{23}$ This might have led to an underestimation of the postnatal growth rates in children with first-trimester fetal growth restriction. Restricting the analyses on birth outcomes to those children with complete fetal and postnatal data did not materially change the associations with the risks of adverse birth outcomes.

Birth weight is the end point of different fetal growth patterns and adverse exposures that may influence fetal growth as early as the first trimester. Previous studies suggested that maternal age, black race, and male sex are associated with longer first-trimester crown to rump length. ${ }^{5,6} \mathrm{We}$ found negative associations of higher diastolic blood pressure and hematocrit with first-trimester crown to rump length. Higher blood pressure in early pregnancy is known to be associated with an increased risk of developing placenta-related problems such as preeclampsia and fetal growth restriction in later pregnancy. ${ }^{24} \mathrm{~A}$ possible explanation is that higher hematocrit levels are indicative of a lower circulating plasma volume, which subsequently might lead to a suboptimal placental perfusion. ${ }^{25}$ Finally, maternal anthropometrics were not associated with firsttrimester crown to rump length, indicating that the previously found associations between maternal weight and birth weight develop in later pregnancy. ${ }^{26}$

Smoking and the nonuse of folic acid supplements were associated with shorter first-trimester growth. Folic acid serves as a substrate for various cellular processes such as cell division and apoptosis, which are implicated in fetal and placental growth and development. ${ }^{27}$ Furthermore, both smoking and folic acid seem to be involved in DNA methylation, which may subsequently affect early fetal and postnatal growth. ${ }^{28}$ There was a strong additive interaction between smoking and folic acid supplement intake. Jauniaux et $\mathrm{al}^{29}$

Figure 2. Associations of First-Trimester Fetal Crown to Rump Length With Growth Characteristics in Later Pregnancy and Early Childhood

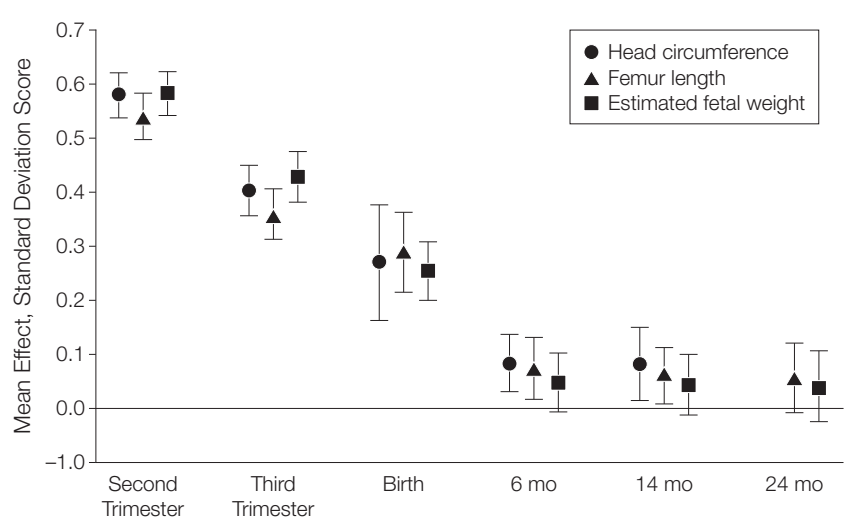

Values are regression coefficients (error bars indicate $95 \%$ confidence intervals) and represent the change (standard deviation score) of head circumference, femur length, and estimated fetal weight per increase of 1 standard deviation in first-trimester fetal crown to rump length. All models are adjusted for fetal sex. Head circumference was not available at 24 months of age.

described that folic acid levels in serum levels and coelomic fluid were lower in smokers than nonsmokers, suggesting that smoking may lead to an impaired bioavailability of folic acid. Smoking during pregnancy also induces morphological and functional changes in the placenta, leading to a reduction of fetal-placental blood flow. ${ }^{30}$ Further studies on the effects of these lifestyle factors on early markers of abnormal placentation, such as pregnancy-associated plasma protein $A$ and free human chorionic gonadotropin- $\beta$, will allow us to examine in greater detail what role placental function plays in the relationship between these factors and early fetal growth. ${ }^{31}$

First-trimester fetal growth restriction was associated with increased risks of prematurity, small size for gestational age at birth, and low birth weight, which are associated with increased perinatal mortality and morbidity. These findings are consistent with results from 2 previous studies, one in spontaneously conceived pregnancies and the other in pregnancies resulting from assisted reproductive technology. ${ }^{9,10}$ Shorter first-trimester crown to rump length may be an intermediate in the pathway between adverse maternal risk factors, such as smoking and nonuse of folic acid supplements, and growth variation in later pregnancy and possibly later life. ${ }^{32}$

Our results indicate that firsttrimester growth variation is associated with growth parameters in early childhood. Smaller first-trimester fetal crown to rump length led to compensatory accelerated postnatal growth. Subsequently, at the age of 24 months there was no longer an association between fetal growth restriction and postnatal growth parameters. Increased postnatal growth rate is a wellestablished risk factor for metabolic and cardiovascular disease in later life. ${ }^{23,33}$ It could be that growth as early as in the first trimester of pregnancy is associated with disease in adulthood, although longer follow-up studies are necessary to examine this relationship.

In conclusion, our study demonstrates that first-trimester fetal growth is associated with several maternal physical characteristics and lifestyle habits. First-trimester growth restriction is associated with higher risks of adverse birth outcomes and accelerated postnatal growth rates. Further studies are needed to assess the associations of first-trimester growth variation on the risks of disease in later childhood and adulthood. 
Author Contributions: Drs Mook-Kanamori and Jaddoe had full access to all of the data in the study and take responsibility for the integrity of the data and the accuracy of the data analysis.

Study concept and design: Steegers, Raat, Hofman, Jaddoe.

Acquisition of data: Mook-Kanamori, Jaddoe. Analysis and interpretation of data: Mook-Kanamori, Steegers, Eilers, Jaddoe.

Drafting of the manuscript: Mook-Kanamori, Steegers. Critical revision of the manuscript for important intellectual content: Mook-Kanamori, Steegers, Eilers, Raat, Hofman, Jaddoe.

Statistical analysis: Mook-Kanamori, Eilers, Jaddoe. Obtained funding: Steegers, Hofman, Jaddoe.

Study supervision: Steegers, Hofman, Jaddoe.

Financial Disclosures: None reported.

Funding/Support: The Generation R Study is conducted by the Erasmus Medical Center in close collaboration with the School of Law and Faculty of Social Sciences of the Erasmus University Rotterdam, the Municipal Health Service Rotterdam area, the Rotterdam Homecare Foundation, and the Stichting Trombosedienst \& Artsenlaboratorium Rijnmond (STAR), Rotterdam, the Netherlands. The first phase of the Generation R Study is made possible by financial support from the Erasmus Medical Center, Rotterdam, the Erasmus University Rotterdam, and the Netherlands Organization for Health Research (ZonMw 21000074). Dr Jaddoe reports receipt of funding from the Netherlands Organization for Health Research (ZonMw 90700303).

Role of the Sponsor: The funding agencies had no role in the design and conduct of the study; nor in the collection, management, analysis and interpretation of the data; nor in the preparation, review, and approval of the manuscript.

Online-Only Material: The eAppendix, 4 eTables, and 2 eFigures are available at http://www.jama .com.

Additional Contributions: We gratefully acknowledge the contribution of general practitioners, hospitals, midwives, and pharmacies in Rotterdam.

\section{REFERENCES}

1. Kuzawa CW. Fetal origins of developmental plasticity: are fetal cues reliable predictors of future nutritional environments? Am J Hum Biol. 2005; 17(1):5-21.

2. Gluckman PD, Hanson MA, Cooper C, Thornburg $\mathrm{KL}$. Effect of in utero and early-life conditions on adult health and disease. N Engl J Med. 2008;359(1): 61-73

3. Larsen WJ, Sherman LS, Potter SS, Scott WJ. Human Embryology. In: Livingstone C, ed. 3rd rev ed. Philadelphia, PA: Elsevier; 2001

4. Robinson HP. Sonar measurement of fetal crownrump length as means of assessing maturity in first trimester of pregnancy. Br Med J. 1973;4(5883): 28-31.

5. Bukowski R, Smith GC, Malone FD, et al; FASTER Research Consortium. Human sexual size dimorphism in early pregnancy. Am J Epidemiol. 2007; 165(10):1216-1218.
6. Bottomley C, Daemen A, Mukri F, et al. Assessing first trimester growth: the influence of ethnic background and maternal age. Hum Reprod. 2009; 24(2):284-290.

7. Timmermans S, Jaddoe VW, Hofman A, SteegersTheunissen RP, Steegers EA. Periconception folic acid supplementation, fetal growth and the risks of low birth weight and preterm birth: the Generation R Study. Br J Nutr. 2009;102(5):777785.

8. Jaddoe VW, Verburg BO, de Ridder MA, et al. Maternal smoking and fetal growth characteristics in different periods of pregnancy: the generation $R$ study. Am J Epidemiol. 2007;165(10):12071215.

9. Bukowski R, Smith GC, Malone FD, et al; FASTER Research Consortium. Fetal growth in early pregnancy and risk of delivering low birth weight infant: prospective cohort study. BMJ. 2007;334(7598): 836.

10. Smith GC, Smith MF, McNay MB, Fleming JE. Firsttrimester growth and the risk of low birth weight. N Engl J Med. 1998;339(25):1817-1822.

11. Jaddoe VW, van Duijn CM, van der Heijden AJ, et al. The Generation R Study: design and cohort update until the age of 4 years. Eur J Epidemiol. 2008; 23(12):801-811.

12. National Collaborating Centre for Women's and Children's Health. NICE clinical guidelines: antenatal care: routine care for the healthy pregnant woman. http://www.nice.org.uk/nicemedia/pdf /CG62FullGuidelineCorrectedJune2008July2009 .pdf. Accessed December 14, 2009.

13. Mukri F, Bourne T, Bottomley C, Schoeb C, Kirk E, Papageorghiou AT. Evidence of early firsttrimester growth restriction in pregnancies that subsequently end in miscarriage. BJOG. 2008;115 (10): $1273-1278$.

14. Troe EJ, Raat $H$, Jaddoe VW, et al. Explaining differences in birthweight between ethnic populations: the Generation R Study. BJOG. 2007;114(12): 1557-1565

15. Royal College of Obstetricians and Gynaecologists. Ultrasound Screening Guideline. http://www.rcog org.uk/womens-health/clinical-guidance /ultrasound-screening. Accessed December 14, 2009

16. Verburg BO, Steegers EA, De Ridder M, et al. New charts for ultrasound dating of pregnancy and assessment of fetal growth: longitudinal data from a population-based cohort study. Ultrasound Obstet Gynecol. 2008:31(4):388-396.

17. Hadlock FP, Harrist RB, Carpenter RJ, Deter RL, Park SK. Sonographic estimation of fetal weight: the value of femur length in addition to head and abdomen measurements. Radiology. 1984;150(2):535540 .

18. Verburg BO, Mulder PG, Hofman A, Jaddoe VW, Witteman JC, Steegers EA. Intra- and interobserver reproducibility study of early fetal growth parameters. Prenat Diagn. 2008;28(4):323-331.

19. Usher R, McLean F. Intrauterine growth of liveborn Caucasian infants at sea level: standards obtained from measurements in 7 dimensions of infants born between 25 and 44 weeks of gestation. J Pediatr. 1969;74(6):901-910.
20. Liu Y, Gold EB, Lasley BL, Johnson WO. Factors affecting menstrual cycle characteristics. Am J Epidemiol. 2004;160(2):131-140.

21. Savitz DA, Terry JW Jr, Dole N, Thorp JM Jr, Siega-Riz AM, Herring AH. Comparison of pregnancy dating by last menstrual period, ultrasound scanning, and their combination. Am J Obstet Gynecol. 2002;187(6):1660-1666.

22. Nohr EA, Frydenberg $M$, Henriksen TB, Olsen J. Does low participation in cohort studies in duce bias? Epidemiology. 2006;17(4):413418.

23. Leunissen RW, Kerkhof GF, Stijnen T, HokkenKoelega A. Timing and tempo of first-year rapid growth in relation to cardiovascular and metabolic risk profile in early adulthood. JAMA. 2009;301(21):2234 2242

24. Poon LC, Kametas NA, Pandeva I, Valencia C, Nicolaides KH. Mean arterial pressure at $11(+0)$ to 13 $(+6)$ weeks in the prediction of preeclampsia. Hypertension. 2008;51(4):1027-1033.

25. Aardenburg R, Spaanderman ME, Ekhart $T H$, van Eijndhoven HW, van der Heijden OW, Peeters LL. Low plasma volume following pregnancy complicated by pre-eclampsia predisposes for hypertensive disease in a next pregnancy. BJOG. 2003;110(11):10011006

26. Kirchengast S, Hartmann B. Maternal prepregnancy weight status and pregnancy weight gain as major determinants for newborn weight and size. Ann Hum Biol 1998.25(1):17-28.

27. Steegers-Theunissen RP, Smith SC, Steegers EA Guilbert LJ, Baker PN. Folate affects apoptosis in human trophoblastic cells. BJOG. 2000:107(12):1513 1515.

28. Breton $C V$, Byun HM, Wenten M, Pan F, Yang $A$, Gilliland FD. Prenatal tobacco smoke exposure affects global and gene-specific DNA methylation. Am J Respir Crit Care Med. 2009;180(5):462467.

29. Jauniaux E, Johns J, Gulbis B, Spasic-Boskovic O Burton GJ. Transfer of folic acid inside the firsttrimester gestational sac and the effect of materna smoking. Am J Obstet Gynecol. 2007;197(1):58 e51-56.

30. Zdravkovic T, Genbacev O, McMaster MT, Fishe $\mathrm{SJ}$. The adverse effects of maternal smoking on the human placenta: a review. Placenta. 2005:26(suppl A): S81-S86.

31. Dugoff L, Hobbins JC, Malone FD, et al. Firsttrimester maternal serum PAPP-A and free-beta subunit human chorionic gonadotropin concentrations and nuchal translucency are associated with obstetric complications: a population-based screening study (the FASTER Trial). Am J Obstet Gynecol. 2004;191 (4):1446-1451.

32. Ong KK, Preece MA, Emmett PM, Ahmed ML, Dunger DB; ALSPAC Study Team. Size at birth and early childhood growth in relation to maternal smoking, parity and infant breast-feeding: longitudinal birth cohort study and analysis. Pediatr Res. 2002;52 (6):863-867.

33. Ekelund $U$, Ong KK, Linne $Y$, et al. Association of weight gain in infancy and early childhood with metabolic risk in young adults. J Clin Endocrinol Metab. 2007;92(1):98-103. 